\title{
C. perfringens challenge reduces matrix metalloproteinase activity in the jejunal mucosa of Eimeria-infected broiler chickens
}

\author{
Lore Van Damme ${ }^{1}$, , Natasja Cox ${ }^{1}$, Chana Callens ${ }^{1}$, Freddy Haesebrouck ${ }^{1}$ (]) Michelle Dargatz², \\ Richard Ducatelle ${ }^{1} \mathbb{B}$, Filip Van Immerseel ${ }^{1 *}$ (i) and Evy Goossens ${ }^{1}$ (i)
}

\begin{abstract}
Matrix metalloproteinases (MMPs) play an important role in intestinal extracellular matrix homeostasis. An overexpression of MMPs results in tissue destruction and local inflammation and has been associated with multiple inflammatory diseases. These host proteases might also be important in tissue damage caused by infectious agents, such as in intestinal damage in Clostridium perfringens-induced avian necrotic enteritis (NE). The aim of the present study was to elucidate the effect of a C. perfringens infection on the MMP activity in the small intestine of birds with a pre-disposing coccidial infection to obtain a more thorough understanding of the pathogenesis of NE. For this purpose, the gelatinolytic activity present in jejunal tissue of Eimeria infected birds which were challenged with either a pathogenic $C$. perfringens type $\mathrm{G}$ strain or a commensal C. perfringens type A strain was analyzed using substrate zymography. The results show that infection of broilers with Eimeria and different $C$. perfringens strains, independent of their pathogenicity, decreases the expression of a 40-45 kDa host collagenase in the jejunum, as compared to the expression in Eimeria-infected control birds. It was also shown that the expression of 2 MMPs with molecular weights of approximately 50-60 and 60-70 kDa was significantly lower in necrotic tissue as compared to the activity in macroscopically healthy tissue adjacent to the lesion. These results indicate that host collagenases are not elicited by the C. perfringens infection for permeabilizing the host mucosa to allow penetration of the NetB toxin in Eimeria infected broilers.
\end{abstract}

Keywords: broiler, Clostridium perfringens, Eimeria, gut, matrix metalloproteinases, necrotic enteritis

\section{Introduction}

Necrotic Enteritis (NE) is one of the most common and financially devastating bacterial diseases in the modern poultry industry $[1,2]$. The disease is caused by netBpositive $C$. perfringens strains and is characterized by severe necrosis and inflammation of the small intestine [3-5]. The pore-forming toxin NetB is an essential virulence factor in the development of necrotic ulcers which are typical for NE in broilers [4]. Where and how NetB

\footnotetext{
*Correspondence: Filip.VanImmerseel@UGent.be

1 Department of Pathology, Bacteriology and Avian Diseases, Faculty of Veterinary Medicine, Ghent University, Merelbeke, Belgium

Full list of author information is available at the end of the article
}

initiates damage is hitherto not determined. It is currently believed that NetB is not involved in early disease pathogenesis and targets deeper layers of the intestinal mucosa rather than superficial structures [6]. Therefore, initial breakdown or permeabilization of the mucosal layer might be required in order for NetB to exert its action. This permeabilization can be either a direct effect on the host tissues of $C$. perfringens virulence factors other than NetB, or it can be a host response elicited indirectly by $C$. perfringens.

Overexpression of host collagenases has been associated with intestinal tissue destruction in several gastrointestinal inflammatory diseases in humans, including Crohn's disease, ulcerative colitis and several forms of

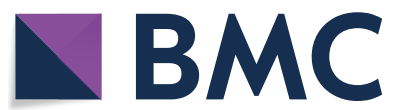

(c) The Author(s) 2020. This article is licensed under a Creative Commons Attribution 4.0 International License, which permits use, sharing, adaptation, distribution and reproduction in any medium or format, as long as you give appropriate credit to the original author(s) and the source, provide a link to the Creative Commons licence, and indicate if changes were made. The images or other third party material in this article are included in the article's Creative Commons licence, unless indicated otherwise in a credit line to the material. If material is not included in the article's Creative Commons licence and your intended use is not permitted by statutory regulation or exceeds the permitted use, you will need to obtain permission directly from the copyright holder. To view a copy of this licence, visit http://creativeco mmons.org/licenses/by/4.0/. The Creative Commons Public Domain Dedication waiver (http://creativecommons.org/publicdomain/ zero/1.0/) applies to the data made available in this article, unless otherwise stated in a credit line to the data. 
gastro-intestinal cancer [7-11]. These host collagenases might also be important in tissue damage caused by infectious agents, such as in intestinal damage in NE. Indeed, collagen is widely distributed throughout the gastrointestinal tract and is an integral component of the connective tissue and basement membrane of the intestinal mucosal layer [12-14]. Disruption of this structural protein may result in loss of tissue integrity and allow penetration of bacterial toxins to deeper tissues and so contribute to subsequent tissue necrosis [15]. Furthermore, Olkowski and colleagues showed an increased MMP activity in necrotic tissue of broilers which were challenged with NE-producing C. perfringens strains as compared to tissue of non-challenged birds [16].

$\mathrm{NE}$ is a multifactorial disease and outbreaks of NE are almost exclusively found to co-occur or follow upon a predisposing coccidial infection [17-21]. During coccidiosis, Eimeria spp. colonize the intestine and destroy epithelial cells as a consequence of the intracellular stages of their lifecycle [20]. Eimeria induces leakage of serum proteins in the lumen of the gut and increases mucus secretion. Both mucus and serum proteins are rich sources of nutrients which $C$. perfringens can exploit for proliferation and toxin production [22, 23]. In addition to providing nutrients for $C$. perfringens, a predisposing Eimeria infection also has tremendous effects on the intestinal tissue itself by shortening of the villi [24], inducing inflammation [25], reducing the activity of digestive enzymes and disrupting tissue integrity [20]. In order to fully characterize the events that contribute to disease pathogenesis, even under experimental settings, this predisposing coccidial infection should be taken into account.

Therefore, the aim of the present study was to focus on the host response to $C$. perfringens, trying to elucidate the effect of a C. perfringens infection on the host MMP activity in the small intestine of birds in the presence of a coccidial infection, known to be a crucial predisposing factor for NE.

\section{Materials and methods}

\section{Bacterial strains and culture conditions}

Two different $C$. perfringens strains were used. Strain 56 was originally isolated from the gut of a NE-affected broiler and is characterized as a toxinotype $\mathrm{G}$ strain. The strain is able to express NetB toxin and is routinely used to induce NE in an in vivo infection model in broilers [26]. Strain JIR4857 is characterized as a commensal toxinotype A strain and cannot express NetB toxin. The inoculum for the oral infection of chickens was prepared by culturing both strains anaerobically overnight at $37{ }^{\circ} \mathrm{C}$ in brain heart infusion broth (Oxoid, Basingstoke, UK).

\section{Necrotic enteritis trial}

The in vivo NE model used in this trial was based on a previously described study [27]. In short, 1-day-old unvaccinated Ross 308 broilers were randomly allocated to 3 different treatment groups with 27 birds/pen (4 replicate pens challenged with strain CP56, 1 pen challenged with the commensal $C$. perfringens strain JIR4857 and 1 pen with control birds, which were not challenged with $C$. perfringens). All broilers were fed a wheat/rye-based (43\%/7.5\%) diet supplemented with soybean meal as a protein source. From day 17 on, the diet was altered with fishmeal (30\%) replacing the soy bean meal as a protein source. These diets contain high levels of proteins and non-starch polysaccharides which predispose chicken to the development of NE. Mild immunosuppression was induced by administering the commercial Nobilis Gumboro D78 vaccine, containing attenuated infectious bursal disease virus, on days 4 and 9 (MSD Animal Health). On days 14 and 16 , all animals received a tenfold dose of live attenuated Eimeria vaccines, respectively Hipracox (containing 5 Eimeria species: E. tenella, E. acervulina, E. maxima, E. praecox and E. mitis) (Hipra, Melle, Belgium) and Paracox-8 (containing 7 Eimeria species: E. acervulina, E.brunetti, E. maxima, E. mitis, E. necatrix, E. praecox and E. tenella) (MSD Animal Health, Brussels, Belgium), to induce a predisposing coccidial infection. On days 18,19 and 20 , birds in the first group were challenged with approximately $5 \times 10^{8} \mathrm{CFU}$ of netB-positive $C$. perfringens strain 56 . Birds in the second and third group received the same predisposing factors as the first group but were inoculated on day 18, 19 and 20 with respectively $5 \times 10^{8} \mathrm{CFU}$ of netB-negative $C$. perfringens strain JIR4857 or sterile bacterial growth medium. On day 21, all animals were euthanized.

At necropsy, NE severity was evaluated by scoring lesions in the small intestine (duodenum, jejunum, ileum) as previously described by Keyburn et al. [28] as follows: score $0=$ no lesions, score $2=$ focal necrosis or ulcerations $(1-5$ foci), score $3=$ focal necrosis or ulcerations $(6-15$ foci), score $4=$ focal necrosis or ulcerations ( $\geq 16$ foci), score $5=$ patches of necrosis of $2-3 \mathrm{~cm}$ long, score $6=$ diffuse necrosis. Birds with a lesion score of 2 or more were considered NE positive. From each scoring class, jejunal lesion tissue (except for scoring class 0 ) and macroscopically unaffected tissue, $1 \mathrm{~cm}$ adjacent to the lesion of 5 different animals was collected. The samples that were collected from $\mathrm{NE}$-affected birds were derived from 2 different pens ( 5 samples were collected from pen 1, 4 samples 
were collected from pen 2). The samples were stored at $-20{ }^{\circ} \mathrm{C}$.

\section{Protein extraction}

Proteins were extracted from the intestinal tissue using mechanical lysis. Briefly, $\pm 27 \mathrm{mg}$ of intestinal tissue was mixed with $400 \mu \mathrm{L}$ TBS-1\% NP-40 [50 mM Tris/HCl, pH 8.0, $150 \mathrm{mM} \mathrm{NaCl}$ and $1 \%(\mathrm{v} / \mathrm{v})$ NP-40 supplemented with EDTA-free protease inhibitor cocktail (Complete, Roche, Mannheim, Germany)]. The mixture was homogenized by grinding with $2.3 \mathrm{~mm}$ zircon/silica and $3.2 \mathrm{~mm}$ stainless steel beads (BioSpec Products, Bartlesville, OK, USA) in a bead beater (twice for $1.5 \mathrm{~min}, 22.5 \mathrm{~Hz}$; TissueLyser) with a $30 \mathrm{~s}$ interval between shakings. Subsequently, samples were centrifuged for $10 \mathrm{~min}$ at $8000 \times g$ and the supernatant was transferred to a new tube. Protein concentration was measured using the BCA protein assay (Thermo Fisher Scientific, Merelbeke, Belgium) and samples were stored at $-20^{\circ} \mathrm{C}$ until further analysis.

\section{Zymography}

The gelatinolytic activity in the intestinal tissue lysates collected from the NE trial was analyzed using gelatin zymography. Briefly, aliquots containing $60 \mu \mathrm{g}$ of protein of each sample were mixed with $2 \times$ loading buffer (0.5 M Tris-HCl pH 6.8, 20\% glycerol, 4\% SDS, a pinch of bromophenol blue) and separated on $8 \%$ SDS page containing $0.1 \%$ gelatin under non-denaturing conditions. After separation, the gel was incubated with renaturing buffer $(2.5 \%$ Triton $\mathrm{X}-100,30 \mathrm{~min}$, room temperature) to remove SDS from the gel. This allows the separated enzymes in the gel to renature and autoactivate. Subsequently, the gel was washed with developing buffer $(150 \mathrm{mM} \mathrm{NaCl}, 5 \mathrm{mM} \mathrm{CaCl} 2,0.05 \% \mathrm{NaN} 3$ and $50 \mathrm{mM}$ Tris- $\mathrm{HCl}$ buffer $\mathrm{pH} 7.5$ ) and incubated with fresh developing buffer under continuous shaking at $37^{\circ} \mathrm{C}$ for $18 \mathrm{~h}$. Afterwards, the gel was stained for $1 \mathrm{~h}$ with Coomassie Brilliant Blue (Sigma-Aldrich, Overijse, Belgium) and destained for 20 min with destaining solution $[40 \%$ methanol $(\mathrm{v} / \mathrm{v}), 10 \%$ acetic acid $(\mathrm{v} / \mathrm{v})]$. Activity of gelatin-degrading enzymes is visible as clear colorless bands against a blue background. Gels were scanned using a GS-800 calibrated densitometer and the approximate molecular weight of the present bands and their intensities were determined using the Quantity One software (BioRad, Hercules, CA, USA). The gelatinolytic activity of each band was calculated as $\frac{100}{O D / \mathrm{mm}^{2}}$ and is described in arbitrary units (AU). Six different gelatinolytic bands were observed in the jejunal tissue. The lowest and highest bands were not quantified due to distortion and oversaturation of the bands.

\section{Statistical analysis}

Differences in the occurrence of NE lesions between the different segments of the small intestine of C. perfringens type $\mathrm{G}$ challenged broilers were evaluated by a binary logistic regression analysis using $\mathrm{R}$ statistical software. All other analyses and calculations were performed using GraphPad Prism software (version 5.03, San Diego, CA, USA). A paired Student's $t$ test was used to compare gelatinase activity in necrotic and macroscopically healthy tissue derived from the same bird. For all other data, two-group experiments were analyzed with unpaired Student's t test, whereas one-way ANOVA followed by Tukey's test was used for comparison of more than two groups. Results are presented as mean \pm SEM. Analyses were performed with $95 \%$ confidence intervals and significance was determined as $\mathrm{p} \leq 0.05$.

\section{Results}

Lesions of necrotic enteritis are more prevalent and severe in the jejunum

Broilers of the control group which were not challenged with $C$. perfringens but received all predisposing factors including Eimeria infection did not develop NE $(\mathrm{n}=26)$. Additionally, no necrotic lesions were seen in the intestine of birds challenged with a commensal $C$. perfringens type A strain JIR4857 $(\mathrm{n}=27)$. Only C. perfringens type $\mathrm{G}$ strain CP56 was able to induce necrotic lesions in Eimeria infected birds. Lesions were observed in $85.05 \%$ $(91 / 107)$ of the birds challenged with this netB-positive C. perfringens strain. In NE positive chickens the lesions could be observed in all segments of the small intestine, but were most severe in the jejunum as compared to the duodenum or ileum $(\mathrm{p}<0.0001)$. A significant association was observed between the small intestinal segment and the development of necrotic lesions, with the jejunum being 17.89 to 22.9 times more likely to develop necrotic lesions as compared to the duodenum or ileum, respectively. Moderate enteric lesions (score 3 and 4) were dominant, being present in 68.13\% (62/91) of the affected birds. Lesion score distributions for each segment of the small intestine are summarized in Table 1.

\section{Clostridium perfringens challenge decreases the activity of a specific host collagenase}

As the NE lesions occurred most frequently in the jejunum of broilers, we focused on this section of the small intestine to study the effect of $C$. perfringens challenge on host MMP activity in Eimeria infected birds. The gelatinolytic activity present in jejunal tissue from broilers in the different treatment groups of the NE trial was assessed by gelatin zymography. 
Table 1 Score distribution of necrotic enteritis lesions in the small intestine of 21-day old broilers

\begin{tabular}{|c|c|c|c|c|c|c|c|c|c|}
\hline \multirow[t]{2}{*}{ Group } & \multirow[t]{2}{*}{ Segment } & \multicolumn{6}{|c|}{ Lesion score $^{a}$} & \multirow[t]{2}{*}{ NE positive } & \multirow{2}{*}{$\begin{array}{l}\text { Average } \\
\text { lesion } \\
\text { score }^{c}\end{array}$} \\
\hline & & 0 & 2 & 3 & 4 & 5 & 6 & & \\
\hline \multirow[t]{4}{*}{ Control } & Duodenum & 26 & 0 & 0 & 0 & 0 & 0 & $0 \%(0 / 26)$ & - \\
\hline & Jejunum & 26 & 0 & 0 & 0 & 0 & 0 & $0 \%(0 / 26)$ & - \\
\hline & Ileum & 26 & 0 & 0 & 0 & 0 & 0 & $0 \%(0 / 26)$ & - \\
\hline & Overall & & & & & & & $0 \%(0 / 26)$ & - \\
\hline \multirow[t]{4}{*}{ Type A (JIR 4857) } & Duodenum & 27 & 0 & 0 & 0 & 0 & 0 & $0 \%(0 / 27)$ & - \\
\hline & Jejunum & 27 & 0 & 0 & 0 & 0 & 0 & $0 \%(0 / 27)$ & - \\
\hline & Ileum & 27 & 0 & 0 & 0 & 0 & 0 & $0 \%(0 / 27)$ & - \\
\hline & Overall & & & & & & & $0 \%(0 / 27)$ & - \\
\hline \multirow[t]{4}{*}{ Type G (CP56) } & Duodenum & 85 & 11 & 6 & 4 & 1 & 0 & $20.56 \%(22 / 107)^{A}$ & $2.77^{C}$ \\
\hline & Jejunum & 19 & 7 & 15 & 46 & 18 & 2 & $82.24 \%(88 / 107)^{\mathrm{B}}$ & $3.92^{\mathrm{D}}$ \\
\hline & Ileum & 89 & 6 & 5 & 6 & 0 & 1 & $16.82 \%(18 / 107)^{A}$ & $3.17^{C}$ \\
\hline & Overall & & & & & & & $85.05 \%(91 / 107)$ & 3.91 \\
\hline
\end{tabular}

All birds were challenged with a ten-fold dose of a live attenuated Eimeria vaccine at day 14 and 16 to induce a predisposing coccidiosis infection. On day 18,19 and 20 , birds were challenged with either a pathogenic C. perfringens type G strains (CP56), a commensal C. perfringens type A strain (JIR4857) or sterile bacterial culture medium (control).

a NE lesion scoring of the small intestine was performed as previously described by Keyburn et al. [28].

b NE positive = lesion score $\geq 2$.

c Average lesion score of NE positive birds. Data represents mean $\pm \mathrm{SE}$.

${ }^{d}$ Means within the same column with different superscripts differ significantly $(p<0.05){ }^{A}{ }^{A}$ B binary logistic regression analysis or ${ }^{C, D}$ one-way ANOVA followed by Tukey's multiple comparisons test.

As NE is a complex disease, not all animals are equally affected by NE in experimental trials and field outbreaks. In the current trial, a minority of the birds challenged with the pathogenic, $C$. perfringens type $G$ strain did not develop macroscopic lesions of NE. When focusing on these birds that did not develop NE (i.e. birds without macroscopic intestinal necrosis), significantly lower gelatinase activity of a $40-45 \mathrm{kDa}$ protein was measured in the jejunal tissue of birds challenged with a $C$. perfringens type $\mathrm{A}$ or type $\mathrm{G}$ strain as compared to control chickens receiving only the predisposing Eimeria infection (p-value respectively 0.0317 and 0.0098, Table 2). No difference in gelatin-degrading activity of this $40-45 \mathrm{kDa}$ protein was observed between birds challenged with either the C. perfringens type A or type G strain. Furthermore, $C$. perfringens challenge of Eimeria infected birds did not affect the activity of the other gelatinolytic enzymes in the jejunal tissue (Table 2).

\section{MMP activity is decreased within NE lesions}

In order to assess whether the difference in disease susceptibility between birds within the $C$. perfringens type $G$ strain challenged group might be related to an altered reaction of host MMP activity on the $C$. perfringens challenge, the gelatinolytic activity of macroscopically healthy jejunal tissue of birds that developed NE was compared to birds that did not develop NE, but were infected with the same C. perfringens type G strain. No differences in

Table 2 Gelatinolytic activity of jejunal samples of Eimeria and C. perfringens type A- or type G-infected broilers

\begin{tabular}{|c|c|c|c|c|c|}
\hline \multirow[t]{2}{*}{ Group } & \multirow[t]{2}{*}{ NE } & \multicolumn{4}{|c|}{ Gelatinolytic enzyme, approximate MW } \\
\hline & & $\sim 40-45 \mathrm{kDa}$ & $\sim 50-60 \mathrm{kDa}$ & $\sim 60-70 \mathrm{kDa}$ & $\sim 75-85 \mathrm{kDa}$ \\
\hline Control $(n=5)$ & No & $1.10 \pm 0.054^{\mathrm{A}}$ & $1.19 \pm 0.072$ & $1.03 \pm 0.039$ & $1.09 \pm 0.077$ \\
\hline Type A $(n=5)$ & No & $0.81 \pm 0.083^{B}$ & $1.10 \pm 0.15$ & $1.05 \pm 0.14$ & $1.09 \pm 0.18$ \\
\hline Type $G(n=5)$ & No & $0.74 \pm 0.051^{B}$ & $1.01 \pm 0.086$ & $0.93 \pm 0.063$ & $0.89 \pm 0.087$ \\
\hline Type G $(n=9)$ & Yes & $0.65 \pm 0.030$ & $0.98 \pm 0.045$ & $0.86 \pm 0.051$ & $0.74 \pm 0.045$ \\
\hline
\end{tabular}

Control: Eimeria infected birds, Type A and Type G: Eimeria infected birds challenged with respectively a commensal C. perfringens type A strain (JIR4857) or pathogenic C. perfringens type G strain (CP56). NE: birds without (No) or with (Yes) necrotic enteritis. Gelatinolytic activity of the digested spots is expressed in arbitrary units $=\frac{100}{\mathrm{OD} / \mathrm{mm}^{2}}$. Data represents mean $\pm \mathrm{SE}$. One-way ANOVA followed by Tukey's multiple comparisons test was used to compare the means of the NE $=\mathrm{No}$ groups. Values within the same column with different superscripts differ significantly $(p<0.05)$. 
MMP activities were observed in macroscopically unaffected jejunal tissue of birds suffering from NE as compared to unaffected birds (Table 2).

Additionally, to assess the involvement of host MMPs in lesion development, the MMP activity within the necrotic lesions was compared to the activity in macroscopically unaffected tissue adjacent to the lesions. The activity of two MMPs with a molecular weight of approximately 50-60 and 60-70 kDa (presumably
MMP2 which has a MW of $\sim 62 \mathrm{kDa}$ ) was significantly lower in tissue derived from the lesions as compared to macroscopically unaffected tissue adjacent to the lesions (respectively $\mathrm{p}=0.0107$ and 0.0341 ). No difference in activity of the $40-45 \mathrm{kDa}$ or $75-85 \mathrm{kDa}$ enzymes was observed (Figure 1).

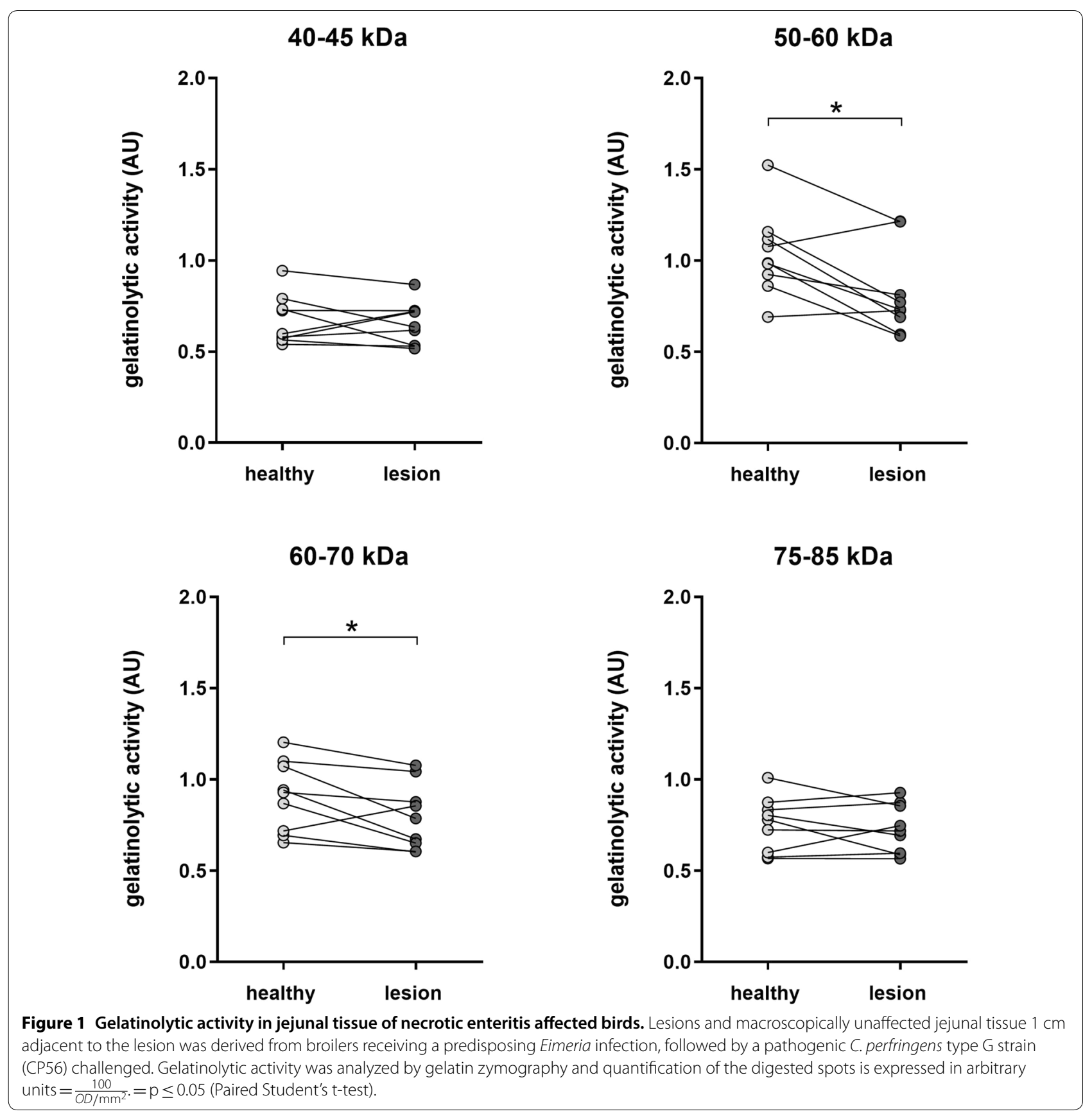




\section{Discussion}

MMPs play an important role in degrading components of the extracellular matrix and basement membrane [29]. In addition to ECM degradation, MMPs are involved in multiple physiological processes, like innate and adaptive immunity and inflammation, by regulating the release and activation of cytokines, growth factors, antibiotic peptides and other bioactive molecules [30, 31]. Expression of MMPs is tightly regulated by a complex process of enzyme synthesis, secretion, activation, and inhibition, which results in low basal levels of these enzymes in healthy tissue [32]. Still, an overexpression of host collagenases results in tissue destruction and local inflammation and has been associated with multiple inflammatory diseases and pathological processes [33]. In this study we investigated whether challenge of broiler chickens with either a pathogenic, net $B$-positive or a non-pathogenic, netB-negative $C$. perfringens strain affects the jejunal expression of host-derived MMPs using an experimental model of NE involving a predisposing Eimeria infection.

As expected, only the netB-positive $C$. perfringens type $G$ strain was able to induce NE. Postmortem examinations of NE affected birds showed that necrotic lesions are more prevalent and severe in the jejunum compared to other segments of the small intestine. The distribution of intestinal lesions in the present infection study is in accordance with older studies of both laboratory consignments and field cases of NE [18]. Why this segment of the small intestine is more prone to develop lesions is hitherto unknown.

Clostridial challenge of Eimeria infected birds significantly reduced the gelatinolytic activity in the broiler jejunum as compared to unchallenged Eimeria infected control birds. Indeed, even when no macroscopic lesions were observed, challenge with either a nonpathogenic type A strain or a pathogenic C. perfringens type $\mathrm{G}$ strain both resulted in reduced activity of a specific intestinal collagenase with a molecular weight of 40-45 kDa. Moreover, the activity of two larger MMPs was significantly reduced (an unknown MMP with a MW of 50-60 kDa and a 60-70 kDa MMP, presumably MMP2) in necrotic tissue as compared to the activity in macroscopically healthy tissue adjacent to the lesion. This is in contrast to previous findings from Olkowski et al., where a significant increase of MMP activity was observed in necrotic tissue as compared to the activity in healthy tissue from unchallenged control birds [16]. However, it should be noted that no comparison with unaffected tissue from $C$. perfringens challenged birds was made. Furthermore, Olkowski et al. induced NE by two oral $C$. perfringens inoculations without a preceding Eimeria infection [16]. Yet, coccidiosis plays an important role in the occurrence and severity of outbreaks of NE and is commonly used as a predisposing factor in experimental NE models [17]. Therefore, in the present study, a necrotic enteritis challenge model was used that includes a predisposing Eimeria infection caused by administering an overdose of commercially available coccidial vaccines which is followed by the administration of $C$. perfringens for 3 consecutive days.

Park et al. already demonstrated a differential expression of various genes involved in innate immunity when broilers were co-infected with Eimeria and C. perfringens as compared to challenge with either pathogen alone, suggesting that the host inflammatory response is fundamentally different during dual infection [34]. In the current study, we assessed the effect of $C$. perfringens challenge on host MMP activity, in the presence of a predisposing Eimeria infection. The contradictory findings between the current study and previous results from Olkowski et al. indicate that primary infection with Eimeria might increase the collagenase activity, whereas subsequent $C$. perfringens might dampen this response again. However, no reports are available studying the effect of Eimeria infection on the collagenase activity in the small intestine. Also in the current study no conclusions can be drawn on the effect of single Eimeria infection on host MMP activity, as no unchallenged birds or birds infected with $C$. perfringens alone were used. Nevertheless, our study indicates the importance of using an experimental NE model which resembles the reality in animal farming as close as possible as different models can lead to unexpected contradictory results.

In conclusion, $C$. perfringens challenge reduced the MMP activity in the jejunal tissue of Eimeria infected broilers. These results indicate that host collagenases are not elicited by the $C$. perfringens infection for permeabilizing the host mucosa to allow penetration of the NetB toxin in Eimeria infected broilers. This is in contrast to the previous reported increase of MMP activity in the necrotic lesions of $C$. perfringens challenged birds in the absence of a predisposing Eimeria infection. Further studies are needed to fully characterize the effect of Eimeria challenge, as well as the combined challenge of Eimeria and C. perfringens, on specific MMP activity in the broiler intestine, as compared to uninfected healthy controls. One interesting topic for future work includes the identification of the differential expressed host MMPs that were observed in this study.

\section{Abbreviations}

NE: necrotic enteritis; AU: arbitrary units; MMP: matrix metalloproteinase. 


\section{Acknowledgements}

The authors are thankful for the assistance of the Ph.D. students, post-docs and scientific staff of the Department of Pathology, Bacteriology and Avian Diseases during the conduct of the necrotic enteritis in vivo trial.

\section{Authors' contributions}

Study design: LVD, RD, FVI, EG; Animal experiments: LVD, NC, MD, CC, EG; in vitro experiments: LVD, NC, CC; Preparation of the manuscript: LVD, FH, RD, FVI, EG; All authors offered a critical review of the manuscript. All authors read and approved the final manuscript.

\section{Funding}

EG is supported by the Research Foundation Flanders (FWO) under Grant Number [12W8919N]. The presented work was funded by a Grant from Evonik Nutrition and Care.

\section{Availability of data and materials}

All data are available on request.

\section{Ethical approval and consent to participate}

All experimental procedures involving animals were approved by the ethical committee of the Faculties of Veterinary Medicine and Bioscience Engineering of Ghent University (EC2017/44). Consent to participate is not applicable.

\section{Consent to publish}

Not applicable.

\section{Competing interests}

No potential conflict of interest was reported by the authors.

\begin{abstract}
Author details
${ }^{1}$ Department of Pathology, Bacteriology and Avian Diseases, Faculty of Veterinary Medicine, Ghent University, Merelbeke, Belgium. ${ }^{2}$ Division Nutrition \& Care-Animal Nutrition, Evonik Operations GmbH, Halle, Westfalen 33790, Germany.
\end{abstract}

Received: 4 June 2020 Accepted: 28 July 2020

Published online: 08 August 2020

\section{References}

1. Skinner JT, Bauer S, Young V, Pauling G, Wilson J (2010) An economic analysis of the impact of subclinical (mild) necrotic enteritis in broiler chickens. Avian Dis 54:1237-1240

2. Wade B, Keyburn A (2015) The true cost of necrotic enteritis. World Poult 31:16-17

3. Cooper KK, Songer JG (2009) Necrotic enteritis in chickens: a paradigm of enteric infection by Clostridium perfringens type A. Anaerobe 15:55-60

4. Keyburn AL, Boyce JD, Vaz P, Bannam TL, Ford ME, Parker D, Di Rubbo A, Rood Jl, Moore RJ (2008) NetB, a new toxin that is associated with avian necrotic enteritis caused by Clostridium perfringens. PLoS Pathog. https:// doi.org/10.1371/journal.ppat.0040026

5. Olkowski A, Wojnarowicz C, Chirino-Trejo M, Drew M (2006) Responses of broiler chickens orally challenged with Clostridium perfringens isolated from field cases of necrotic enteritis. Res Vet Sci 81:99-108

6. Parreira VR, Russell K, Athanasiadou S, Prescott JF (2016) Comparative transcriptome analysis by RNAseq of necrotic enteritis Clostridium perfringens during in vivo colonization and in vitro conditions. BMC Microbiol 16:186. https://doi.org/10.1186/s12866-016-0792-6

7. Kirkegaard T, Hansen A, Bruun E, Brynskov J (2004) Expression and localisation of matrix metalloproteinases and their natural inhibitors in fistulae of patients with Crohn's disease. Gut 53:701-709

8. Liabakk NB, Talbot I, Smith RA, Wilkinson K, Balkwill F (1996) Matrix metalloprotease 2 (MMP-2) and matrix metalloprotease 9 (MMP-9) type IV collagenases in colorectal cancer. Cancer Res 56:190-196

9. Murray Gl, Duncan ME, O'Neil P, McKay JA, Melvin WT, Fothergill JE (1998) Matrix metalloproteinase-1 is associated with poor prognosis in oesophageal cancer. J Pathol 185:256-261
10. O'Sullivan S, Gilmer JF, Medina C (2015) Matrix metalloproteinases in inflammatory bowel disease: an update. Mediators Inflamm 2015:964131. https://doi.org/10.1155/2015/964131

11. Verma S, Kesh K, Ganguly N, Jana S, Swarnakar S (2014) Matrix metalloproteinases and gastrointestinal cancers: impacts of dietary antioxidants. World J Biol Chem 5:355-376

12. Frantz C, Stewart KM, Weaver VM (2010) The extracellular matrix at a glance. J Cell Sci 123:4195-4200

13. Graham MF, Diegelmann RF, Elson CO, Lindblad WJ, Gotschalk N, Gay S, Gay R (1988) Collagen content and types in the intestinal strictures of Crohn's disease. Gastroenterology 94:257-265

14. Verbeke S, Gotteland M, Fernandez M, Bremer J, Rios G, Brunser O (2002) Basement membrane and connective tissue proteins in intestinal mucosa of patients with coeliac disease. J Clin Pathol 55:440-445

15. Harrington DJ (1996) Bacterial collagenases and collagen-degrading enzymes and their potential role in human disease. Infect Immun 64:1885-1891

16. Olkowski AA, Wojnarowicz C, Chirino-Trejo M, Laarveld B, Sawicki G (2008) Sub-clinical necrotic enteritis in broiler chickens: novel etiological consideration based on ultra-structural and molecular changes in the intestinal tissue. Res Vet Sci 85:543-553

17. Al-Sheikhly F, Al-Saieg A (1980) Role of coccidia in the occurrence of necrotic enteritis of chickens. Avian Dis 24:324-333

18. Long JR, Pettit JR, Barnum DA (1974) Necrotic enteritis in broiler chickens II. Pathology and proposed pathogenesis. Can J Comp Med 38:467-474

19. Porter RE (1998) Bacterial enteritides of poultry. Poult Sci 77:1159-1165

20. Williams RB (2005) Intercurrent coccidiosis and necrotic enteritis of chickens: rational, integrated disease management by maintenance of gut integrity. Avian Pathol 34:159-180

21. Williams RB, Marshall RN, La Ragione RM, Catchpole J (2003) A new method for the experimental production of necrotic enteritis and its use for studies on the relationships between necrotic enteritis, coccidiosis and anticoccidial vaccination of chickens. Parasitol Res 90:19-26

22. Collier CT, Hofacre CL, Payne AM, Anderson DB, Kaiser P, Mackie RI, Gaskins HR (2008) Coccidia-induced mucogenesis promotes the onset of necrotic enteritis by supporting Clostridium perfringens growth. Vet Immunol Immunopathol 122:104-115

23. Van Immerseel FV, De Buck J, Pasmans F, Huyghebaert G, Haesebrouck F, Ducatelle R (2004) Clostridium perfringens in poultry: an emerging threat for animal and public health. Avian Pathol 33:537-549

24. Kettunen H, Tiihonen K, Peuranen S, Saarinen MT, Remus JC (2001) Dietary betaine accumulates in the liver and intestinal tissue and stabilizes the intestinal epithelial structure in healthy and coccidia-infected broiler chicks. Comp Biochem Physiol A: Mol Integr Physiol 130:759-769

25. Yun CH, Lillehoj HS, Lillehoj EP (2000) Intestinal immune responses to coccidiosis. Dev Comp Immunol 24:303-324

26. Timbermont L, Lanckriet A, Gholamiandehkordi AR, Pasmans F, Martel A, Haesebrouck F, Ducatelle R, Van Immerseel F (2009) Origin of Clostridium perfringens isolates determines the ability to induce necrotic enteritis in broilers. Comp Immunol Microbiol Infect Dis 32:503-512

27. Gholamiandehkordi AR, Timbermont L, Lanckriet A, Van Den Broeck W, Pedersen K, Dewulf J, Pasmans F, Haesebrouck F, Ducatelle R, Van Immerseel F (2007) Quantification of gut lesions in a subclinical necrotic enteritis model. Avian Pathol 36:375-382

28. Keyburn AL, Sheedy SA, Ford ME, Williamson MM, Awad MM, Rood J, Moore RJ (2006) Alpha-toxin of Clostridium perfringens is not an essential virulence factor in necrotic enteritis in chickens. Infect Immun 74:6496-6500

29. Fowlkes JL, Thrailkill KM, Serra DM, Suzuki K, Nagase H (1995) Matrix metalloproteinases as insulin-like growth factor binding protein-degrading proteinases. Prog Growth Factor Res 6:255-263

30. Nagase $H$, Visse R, Murphy G (2006) Structure and function of matrix metalloproteinases and TIMPs. Cardiovasc Res 69:562-573

31. Van den Steen PE, Proost P, Wuyts A, Van Damme J, Opdenakker G (2000) Neutrophil gelatinase B potentiates interleukin-8 tenfold by aminoterminal processing, whereas it degrades CTAP-III, PF-4, and GRO- $a$ and leaves RANTES and MCP-2 intact. Blood 96:2673-2681

32. Caley MP, Martins VL, O'Toole EA (2015) Metalloproteinases and wound healing. Adv Wound Care (New Rochelle) 4:225-234

33. Elkington PTG, O'kane CM, Friedland JS (2005) The paradox of matrix metalloproteinases in infectious disease. Clin Exp Immunol 142:12-20 
34. Park SS, Lillehoj HS, Allen PC, Park DW, FitzCoy S, Bautista DA, Lillehoj EP (2008) Immunopathology and cytokine responses in broiler chickens coinfected with Eimeria maxima and Clostridium perfringens with the use of an animal model of necrotic enteritis. Avian Dis 52:14-22

\section{Publisher's Note}

Springer Nature remains neutral with regard to jurisdictional claims in published maps and institutional affiliations.
Ready to submit your research? Choose BMC and benefit from:

- fast, convenient online submission

- thorough peer review by experienced researchers in your field

- rapid publication on acceptance

- support for research data, including large and complex data types

- gold Open Access which fosters wider collaboration and increased citations

- maximum visibility for your research: over $100 \mathrm{M}$ website views per year

At BMC, research is always in progress.

Learn more biomedcentral.com/submissions 